\title{
AUtomated SURfaCe Finishing OF LARge Diameter STORAGE TANKS
}

\author{
Matthew A. Freund, Alfred E. Traver, Gordon L. Wesley \\ Department of Mechanical Engineering \\ James T. O'Connor, R. Scott Rowland \\ Department of Civil Engineering \\ University of Texas at Austin \\ Austin, Texas 78712 USA
}

\begin{abstract}
Current surface preparation and coating application techniques for large scale steel structures, such as storage tanks, are problematic because they expose workers to substantial safety hazards, extend consuruction and maintenance schedules, and generate significant expense for owners. In order to help mitigate these impacts, a partially automated system to perform blast cleaning and painting operations is under development at the University of Texas. This paper serves to outline the justification for producing such a machine, explain the process by which the system was developed, and provide a preliminary assessment of the prototype device's performance and potential impact in the coating industry.
\end{abstract}

\subsection{INTRODUCTION}

Surface prepardicion and coating operations are perforn $\approx \mathrm{d}$ oì most steel structures during construction and are repeated periodically during the structure's service life. One class of such structures is the storage tanks used in the petrochemical industry to contain a variety of raw materials, intermediate yields, and final products; surface finishing of such tanks is the focus of this paper. As a baseline for discussion, a tank currently under construction on the Gulf Coast of Texas, indicative of current design practices, is illustrated in Figure 1.

Typical surface finishing specifications required blast cleaning to a commercial or nearwhite condition followed by painting with three coats of a two component epoxy: a primer, an intermediate, and a finish coat. Surface finishing operations on storage tanks are currently performed manually by crews working from cable-suspended scaffolds or bosun's chairs. The problems involved with manual execution, which are further detailed in the following section, have prompted industry to look for a better method of accomplishing these tasks. In the course of examining alternative finishing methods, it was found that several previous task identification studies for construction automation $(1,2)$ indicate surface finishing operations are good candidates for automation.

As a result of these findings, the University of Texas Departments of Civil and Mechanical Engineering initiated a cooperative project in the Fall of 1989 to produce an automated blast cleaning and painting system for large diameter storage tanks. This paper examines the justification for producing such a system, outlines the design effort undertaken to develop a prototype machine, presents preliminary results from initial testing of the device, and examines the potential impact of such a system on surface finishing practices.

\subsection{DEFINITION OF NEED}

Many tasks in a wide range of industries have been successfully automated, typically in response to perceived problems in operational safety, labor requirements, production costs, and/or productivity. These same motivating factors exist in the current practice of finishing operations, as outlined below.

Sandblasting and painting operations present a multitude of potential health hazards to the workers performing the operations. Perhaps the most obvious safety hazard is the inherent danger of work above grade. As currently available equipment requires operator presence in close proximity to the workface, 
crews are exposed to the danger of a fall at all times. Indicative of this problem, records of the National Safety Council (3) indicate that fully seventy percent of all serious injury to coating crews are caused by falls.

In addition to the risk of falls, blasing and painting crews are exposed to long-term health hazards posed by process by oducts including the silica dust, old surfece ant, and other residue released while blastre and the chemical fumes released by coating boducts during their application and curing. Methods of crew protection necessitate the use of auxiliary breathing equipment and requires blasting crews to work under heavy clothing and protective helmets. Automation of surface finishing tasks holds potential to reduce or entirely eliminate many of these safety risks.

In addition to the safety concerns above, both sandblasting and painting are expensive operations as they are extremely labor intensive. Table 1 below provides an indication of the average cost, in Houston, Texas, of standard grades of blast cleaning and spray application of coating. Whet considering the surface area of large $\tan \mathrm{ks}$, these costs become quite significant. As human labor is a large component of the to $\mathrm{al}$ cost of finishing operations, automation ho ds the potential for significant cost reduction.

Table 1 Cost of Blast Cleaning and Painting Operations in U.S. Dollars (1990)

Activity
Blast Clean - Commercial
Blast Clean - Near White
Blast Clean - White Metal

Paint - Spraying (per coat)

$\begin{array}{cc}\frac{L a b o r}{c} \text { Cost per m } & \left(/ \mathrm{ft}^{2}\right) \\ \$ 6.46 & (\$ 0.60) \\ \$ 8.50 & (\$ 0.79) \\ \$ 10.33 & (\$ 0.96)\end{array}$

$\$ 1.61$

$(\$ 0.15)$

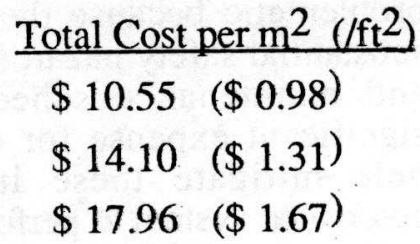

$\$ 3.12(\$ 0.29)$
A final area in which automation holds significant appeal is its potential to increase the productivity of finishing operations. Average productivity levels for a three man crew are shown in Table 2 on the following page. As most project specificitions require work areas to be coated on the same day that they are blasted, the actual swirace area covered per crew-day is even lowi: than the figures below indicate. Such low productivity levels serve both to increase project costs and to extend construction schedules and facility maintenance shutdowns. As an example of this problem, the tank shown in Figure 1 would require over 100 crew-days to blast clean to commercial grade and almost seventy days to spray paint, for a combined total of $170 \mathrm{crew}$-days for exterior coating. While these figures indicate low process productivity, ambient conditions often lower production even further. For example, spray painting operations may only be performed under favorable weather conditions -if the wind is too strong or in an undesirable direction, spray painting is impossible due to the risk of excess paint being carried downwind and adhering to adjacent buildings, automobiles, and other objects. Under such conditions, paint must be manually applied with brushes and rollers and crew productivity is further reduced, as indicated in Table 2. Automation of these tasks may well serve to reduce the schedule duration of finishing projects by providing a more productive blasting and painting methodology.

\subsection{PRoTOTYPE DEVE: OPMENT}

Examination of the faccors outlined above indicate that a strong need exists for an alternative method of performing blast cleaning and painting operations. It was decided early in the project to narrow the project scope to concentrate on finishing the exterior vertical walls of the tank. This area is particularly conducive to automation because it is relatively uniform, represents a significant fraction of the exterior surface area of the tank (thirty-four percent of the tank in Figure 1), and poses the greatest safety risks during manual performance of finishing operations. The following section outlines the development of a machine at theUniversity of Texas at Austin to fulfill this need. This work has been examined in greater depth by Freund, Traver, Wesley, and Rowland (4). 
Table 2 Average Productivity of Blast Cleaning and Painting Crews

Activity

Blast Clean - Commercial

Blast Clean - Near White

Blast Clean - White Metal

Painting - Spray Application

Painting - Brush/Roller Application

\begin{aligned} & Daily Coverage in $\mathrm{m}^{2}\left(\mathrm{ft}^{2}\right) \\ &$\hline 120.8$(1,300) \\ & 96.6(1,040) \\ & 78.5(845) \\ & \\ & 195.1(2,100) \\ & 74.3(800)\end{aligned}$

\subsection{Process Equipment Selection}

In order to facilitate system adoption by current contracting personnel, process equipment was selected with the dual goals of matching industry standards and providing compatibility with a wide variety of coating specifications. An air-entrained sandblasting system, modified to handle two $9.5 \mathrm{~mm}(3 / 8$ inch) nozzles, was purchased for project use. Air-assisted airless spray painting equipment was selected because of its high paint transfer efficiency and low fluid pressure requirements relative to standard airless atomization. This system is extremely flexible and is compatible with most coating formulations in current use.

\subsection{Process Coverage}

The process equipment and supply settings required to establish a stable blast pattern or well-atomized paint fan are easily determined; therefore, the primary concern with respect to process coverage was determination of the ranges of nozzle articulation and travel speeds required for effective surface coverage. This effort was the first stage of experimental research on this project.

A test frame was constructed in which process nozzles could be articulated in various patterns while mounted on a cart moving at controlled speeds. Permutations of motion ranges and cart speeds were evaluated to determine coating thickness and uniformity. To allow evaluation of a wide variety of movement patterns, articulation of the painting nozzles was also modeled in a computer simulation program developed by Freund, Traver, and Alciatore (5)

Appropriate process parameters for sandblasting operations produce a circular blast pattern six $\mathrm{cm}(2.5 \mathrm{in}$.) in diameter at a distance of $66 \mathrm{~cm}(26$ in.) from the nozzle. Blast nozzles are articulated about an axis parallel to the direction of travel in order to attain a single pass coverage width of $61 \mathrm{~cm}(24 \mathrm{in}$.). The degree of blast cleaning achieved is adjusted by varying the travel speed.

For painting operations, nozzle rotation at an offset radius about an axis normal to the workface, as illustrated in Figure 2, was found to provide the most uniform coverage. Each nozzle's orientation with respect to the direction of travel is constant. As with the blasting process, alteration of the system's travel speed is used to vary the applied coating thickness.

\subsection{Process Containment}

Containment of process media and surface residue is an important environmental and safety aspect of the system under development. Cuptailing exhaust of liquid and solid particulate tow the atmosphere will offers substantial improvement in environmental impact over current finishing practices.

Paint overspray containment is of primary importance in order to allow performance of painting operations regardless of ambient environment and weather conditions. A containment system has been built for use on the prototype machine. Containment is accomplished by surrounding the paint nozzles with a hood. Two axial fans mounted in the rear of the hood draw air around the front of the hood, past the spray nozzles, and through a paint filter prior to exhausting to the atmosphere. The filter is capable of removing upwards of ninety-five percent of airborne paint particulates, thereby providing acceptable isolation of the painting process.

Blast process containment is desirable, but is not implemented at this stage in the project due to its tremendous air volume 
processing requirements. When constructed, the containment and collection system will capture blast media and surface contaminants near the workface and entrain them in an airstream. This airstream will be channeled through a cyclone separator, tubular filters, and other processing units prior to release to the atmosphere.

\subsection{System Mobility}

After definition of the process coverage and containment parameters, design work shifted to developing a mobility system to provide straight line motion on the tank surface. Many possible configurations were considered to achieve such mobility, including a large articulated arm and a mobile cart that would adhere to the wall by vacuum or magnetic attraction.

To minimize final system complexity and maximize its reliability, the design team decided to use a cable-supported cart, or carrier module, to which the finishing process module would be attached. However, options still existed regarding the final size of the cart and relative access areas of different configurations. Computer simulation tools were used to analyze these tradeoffs. It was determined that a carrier unit supported by splayed cables best meets the overall process mobility and stability requirements. Carrier motion is regulated by controlling the relative velocities of the two supporting cables. An illustration of the final system configuration is provided in Figure 3. The machine moves in a vertical path while blasting or painting $\sin ^{4}$ translate horizontally at the top or bottom of tie rank to position for the next pass.

The support cables are attached to struts that are temporarily connected to the tank's wind girts. Cable length is regulated by hoists, powered by direct current servo motors, located on the carrier module. Maximum displacement between the supporting struts will increase in proportion to the tank diameter, as will the accessible surface area for one position of the struts. In operation on the tank shown in Figure 1, the machine will be supported at points $21.3 \mathrm{~m} \mathrm{(70} \mathrm{ft.)} \mathrm{apart,} \mathrm{thereby} \mathrm{providing}$ access to one day's work area of 278 square meters (3000 sq. ft.) without repositioning.

\subsection{System Control}

System control, including hoist servo motor speed and process initiation/termination, is handled by an IBM PC AT. Software was developed that determines the accessible work area for a given tank and support configuration, calculates the cable velocities required to produce the desired carrier motion, generates a command file containing both velocity profiles and process actuation instructions, and downloads data to an axis controller and motor drive units.

The maximum allowable splay width of the cables is determined based on the geometry of the tank and the distance from the cable connection points to the tank wall. From this splay width, the accessible work area, a function of several limiting constraints including the maximum allowable cable tension and the minimum required normal foree to the tank wall, is determined. Once the work area is defined, the cable speeds and directions required to move the carrier along a specified path on the tank surface are calculated. Finally, velocity commands for the axis controller are written based upon the cable speeds and process actuation points.

The velocity commands for several different carrier paths may be generated off-line and downloaded to the axis controller thru a serial port. However, initial positioning of the carrier unit, achieved by sending position commands directly to the axis controller, is generally required before command sequences are executed. The position commands sent directly to the controller do not interfere with command files stored in the axis controller.

Once the axis controller begins executing a sequence of velocity commands, process activation and termination is controlled by commands included in the command file. Sigrials are output at the beinning and end of each vertical pass to activare and deactivate the pneumatic controls of in process being performed. Process pericrmance is halted while the cart is being pcsitioned for its next vertical pass. The positional errors resulting from rounding of intermediate velocities is eliminated at the end of each vertical pass by use of posicion control methods. Consequentially, iruaced positional errors are not propagated thru subsequent carrier movements. At the end of a command sequence, the machine terminates all operation and awaits further instruction.

\subsection{SySTEM TESTING}

Initial system testing of the prototype system described above was performed in late March on a mock tank wall built at the 
University of Texas. Carrier mobility, process coverage, paint overspray containment, and the control systems functionality were tested. Several illustrations of the prototype system in operation are provided in this paper. In these trials, the hoists are located at ground level with the cables running over a pulley at the end of the support arms before continuing to the carrier unit. Figure 4 shows the machine configured for sandblasting operations and Figure 5 shows the machine in a painting configuration.

The trials conducted and system performance to date, while insufficient to answer all questions regarding the machine's final performance, do serve to validate the general system implementation. At the submittal time for this paper, several machine modifications to facilitate field use, including transfer of the hoists to the carrier unit, are being made prior to initiation of field testing in April, 1991.

\subsection{Conclusions}

This system was developed in response to perceived problems in operational safety, labor requirements, production expense, and productivity of current finishing operations. Initial analysis indicates that the machine achieves its goals of mitigating these problems.

The primary motivating factor in system development was reduction of the safety hazards associated with sandblasting and painting operations. The system developed fulfills this goal as it reduces operator exposure to above grade, work from eight hour per day to brief intervals required to reposition the support struts for a new work area. The frequency of: this occurrence may be as low as once per day, assuming the tank is of sufficient diameter. By reducing the operator's above grade exposure time, accident frequency may be presumed to decline. Additionally, the machine removes the process operator from close proximity to the blast and spray nozzles and their associated effluent, thereby reducing the health risks associated with such exposure. The system may also reduce the long term effects of excessive noise exposure.

A second reason for development of the automated finishing system was the possibility of reducing the cost of finishing operations. As the machine has been designed to allow replacement of two finishing crews of three men each with two machine operators, a labor reduction of four crew members has been realized. With an average wage of U.S. $\$ 19.00$ per hour, the net savings are U.S. $\$ 600$ per day less the cost of the machine (assuming material and operating expenses remain constant). It is obvious that substantial operational cost savings are possible with the use of this finishing system.

The final factor leading to development of the automated finishing system was the potential productivity savings that could be accrued by such a device. As the machine may work at a much higher duty cycle than humans, does not lose time in repositioning, and does not required daylight conditions for utilization, automated operation allows many possibilities for schedule compression. Additionally, as the machine is not sensitive to surrounding conditions, it would be possible for multiple systems to work on the same tank in closer proximity to one another than is currently possible with manual operations.

The general goals for system development appear to have been met by the machine's performance to date. Future work on the system will concentrate on further testing and refinement of navigational ability and finishing operations. Planned activities include implementation of blast process containment and real time monitoring of process performance parameters to allow compensatory adjustments in travel velocity and nozzle articulation. As new applications are added to the process module inventory additional system constraints will be imposed, but it is believed that the requirements for a particular combination of materials, processes, and motions can be met provided the weight and velocity limitations of the carrier unit are not exceeded.

In general, automation and robotic systems have' not successfully made the transition from the laboratory and and manufacturing sector into field construction as the demands of the construction environment present many unique challenges to such systems. However, applications exist within the current construction arena that are amiable to effective automation by dedicated systems. The critical requirements for such automation are proper task identification and limitation of their scope of operation. It is hoped that the development and testing of this automated finishing system will help prove the functionality of automated construction systems for use in the current construction field environment. 


\section{ACKNOWLEDGEMENTS}

The work described in this paper is jointly funded by the Texas Advanced Research Program and the Construction Industry Institute, located in Austin, Texas, both of whose support is gratefully acknowledged.
The research team would also like to thank the many individuals in the coating industry who have helpfully' offered suggestions and willingly shared their expertise in the course of this project.

\section{REFERENCES}

1. Halpin, D. W., R. Kangari, M. Abraham, D. F. McCahill, Robotics Feasibility in the Construction Industry, Final Report, National Science Foundation Grant \# CEE8696051, 1987.

2. Tucker, R. L., "High Payoff Areas for Automation in Construction," Proceedings of the 5th International Symposium on Robotics in Construction, June 6-8, 1988, Tokyo, pp. 9-16.

3. ----, "Identifying and Controlling Job Hazards during Climbing and High Work," Journal of Protective Coatings and Linings, Vol. 7, No. 10, October 10, 1990, p.p. 69-71.

4. Freund, M., A. E. Traver, G. L. Wesley, R. Scott Rowland, "Automated Finishing of Large Storage Tanks: A Case Study," American Society of Mechanical Engineers, Paper \# 91PET-34, January, 1991.

5. Freund, M., A. E. Traver, D. G. Alciatore, "Simulation of Multiple Nozzle Surface Finishing Operations," American Society of Mechanical Engineers, Paper \# 91-PET-33, January, 1991. 


\section{Figures}

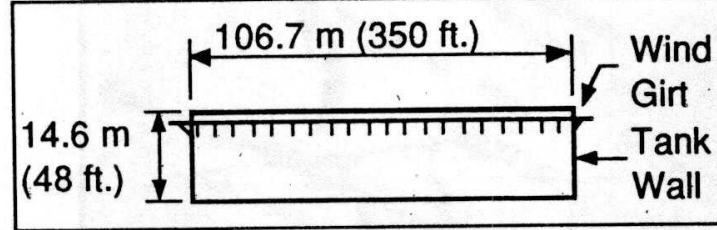

Figure 1 Typical Floating Roof Tank

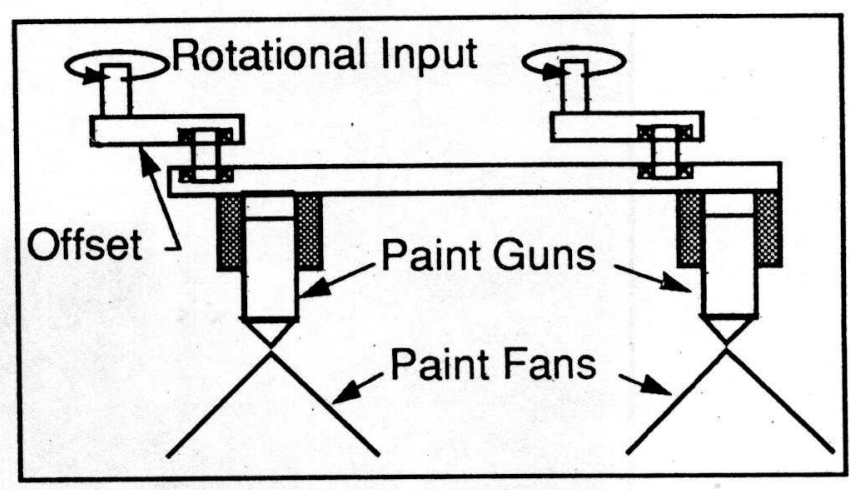

Figure 2 Painting Nozzle Articulation

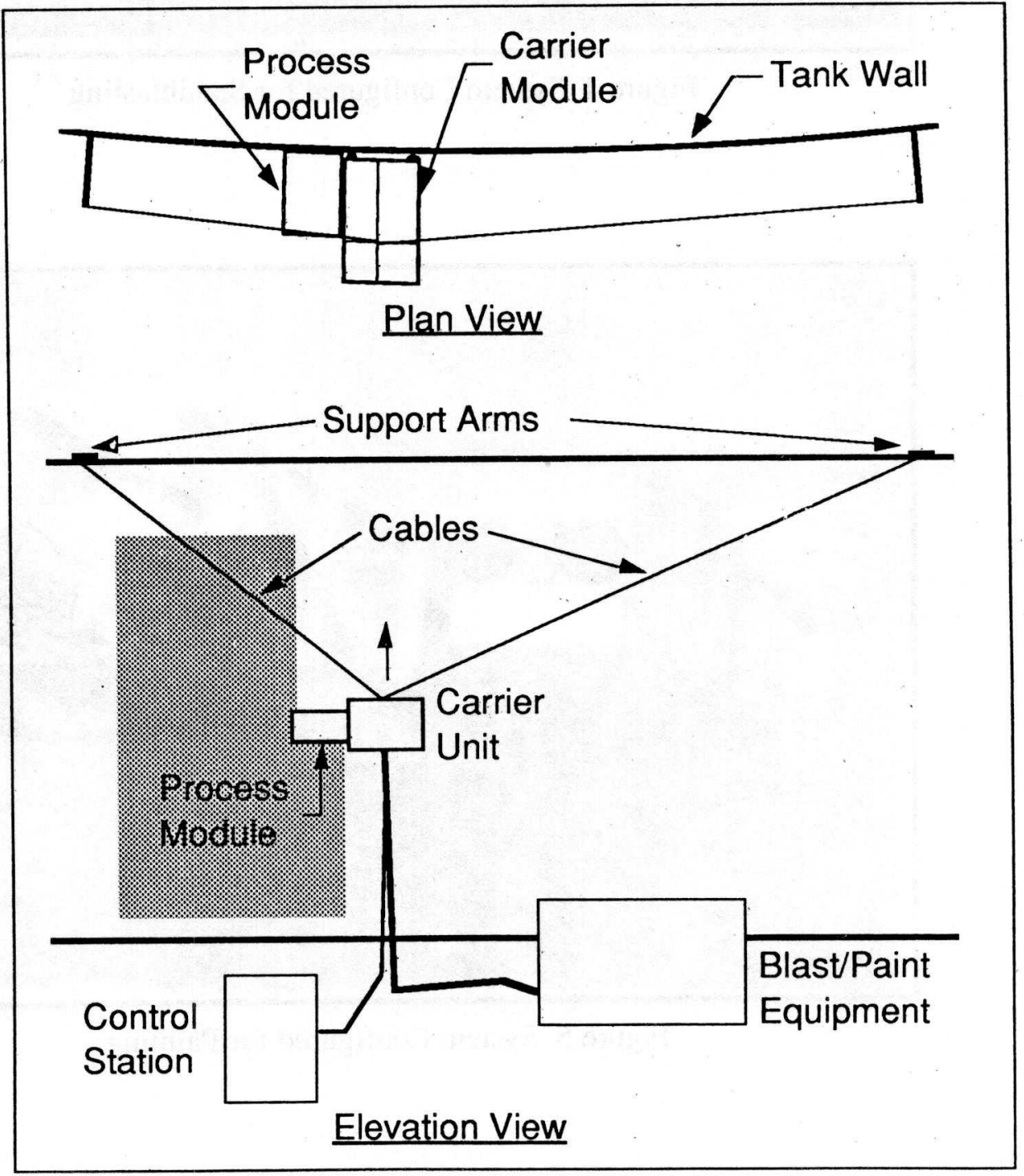

Figure 3 Carrier Mobility Scheme 


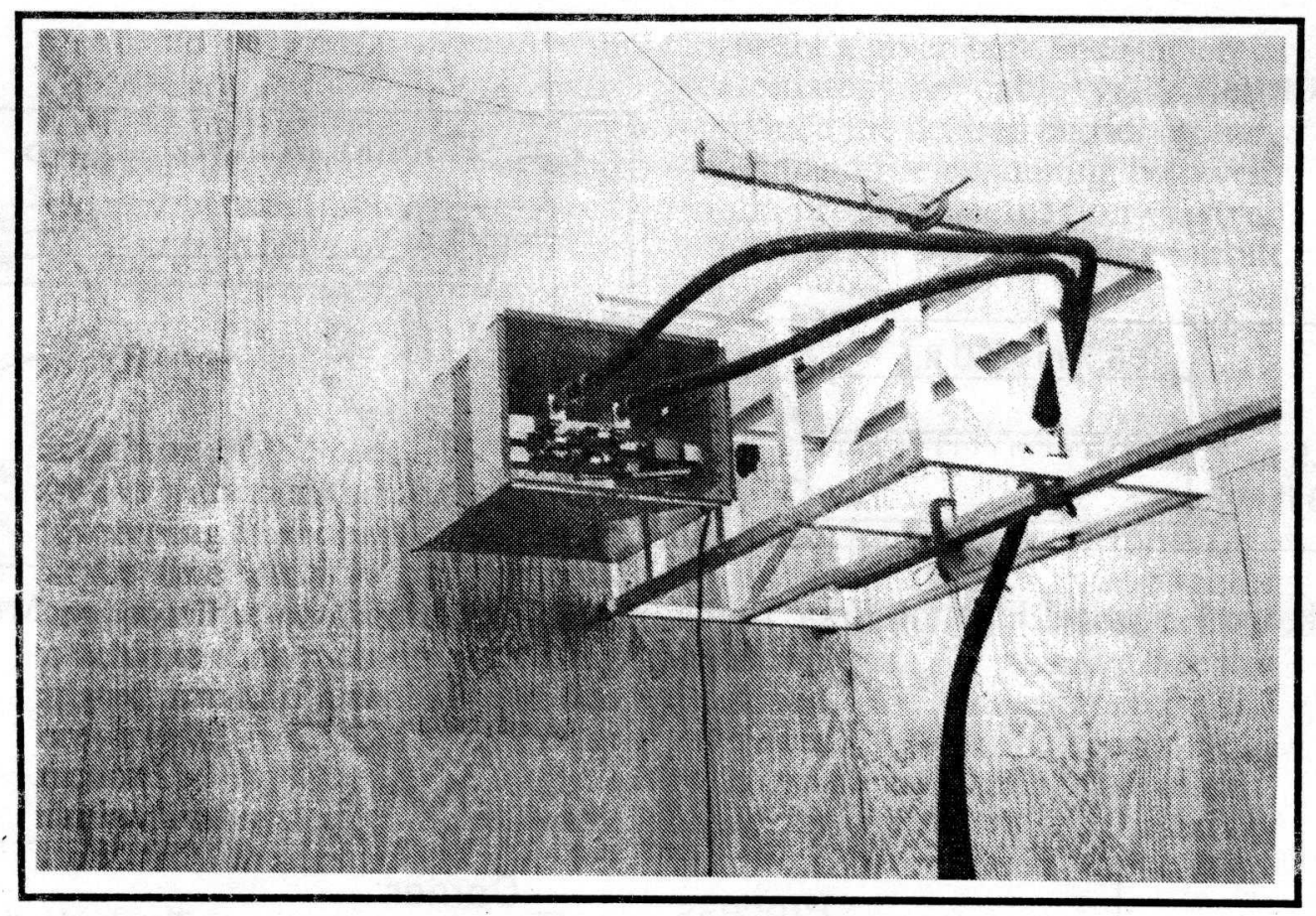

Figure 4 System Configured for Sandblasting

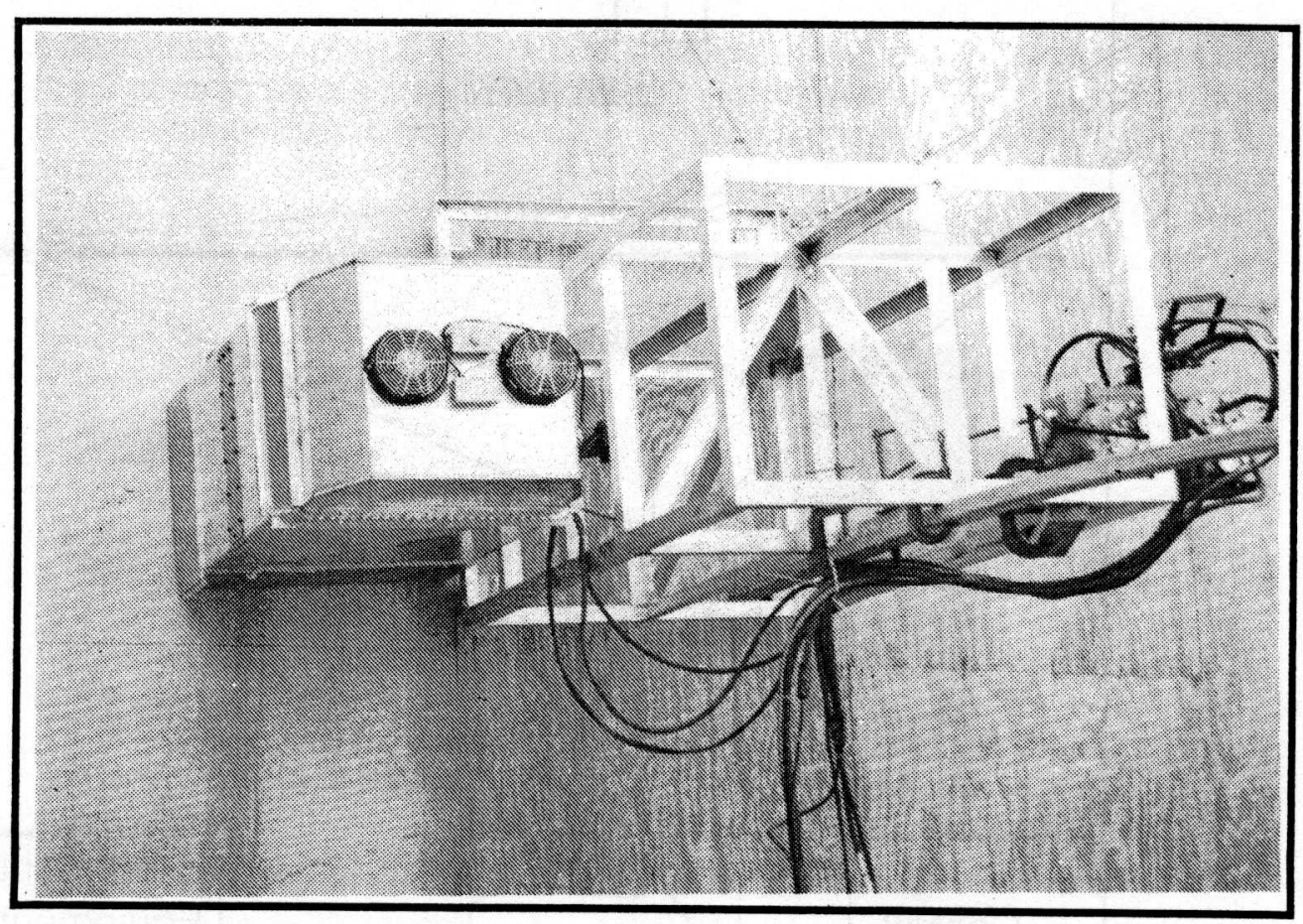

Figure 5 System Configured for Painting 